\title{
Do policy clashes between the judiciary and the executive affect public opinion? Insights from New Delhi's odd-even rule against air pollution
}

\author{
Liam F. Beiser-McGrath ${ }^{1 *}$ (D), Thomas Bernauer ${ }^{2}$ and Aseem Prakash ${ }^{3}$ \\ ${ }^{1}$ Department of Politics, International Relations, and Philosophy, Royal Holloway, University of London, \\ United Kingdom, ${ }^{2}$ Center for Comparative and International Studies and Institute of Science, Technology \\ and Policy (ISTP), ETH Zürich, Switzerland and ${ }^{3}$ Department of Political Science, University of \\ Washington, United States of America \\ ${ }^{\star}$ Corresponding author. E-mails: liam@liambeisermcgrath.com, liam.beiser-mcgrath@rhul.ac.uk
}

(Received 18 June 2020; revised 23 March 2021; accepted 3 June 2021; first published online 08 November 2021)

\begin{abstract}
Policy processes are affected by how policymakers assess public support for a policy. But is public support for a given policy itself affected by characteristics of the policy process, such as cooperation or confrontation amongst policy actors? Specifically, if different branches of government hold conflicting positions on a given policy, do clashes affect public support for the policy? To address this question, we exploit an unexpected clash amongst the executive and judiciary in New Delhi, between survey waves, over exemptions for women in the context of the odd-even rule, a policy intervention to reduce air pollution from transportation. We find that public support for the contested policy was not undermined by the executive-judiciary clash. However, the clash polarised public opinion by gender, based upon the policy exemptions. Our findings shed new light on the broader question of how conflicts amongst different parts of government influence mass public policy preferences.
\end{abstract}

Key words: air pollution; China; India; policy feedback; public opinion; regulation; vehicles

\section{Introduction}

Research in public policy has generated a wealth of insights into the behaviour of policymakers and political institutions, and the policies resulting from governmental decision-making processes. One part of this research effort has focused on understanding the determinants of citizens' policy preferences and how these preferences enable or constrain the design, adoption, and implementation of policies in a wide range of areas. The presumption underpinning this literature is that public opinion should and does influence the choices of policymakers (Brooks and Manza 2007) - even though influence by interest groups at times tends to induce

(C) The Author(s), 2021. Published by Cambridge University Press. This is an Open Access article, distributed under the terms of the Creative Commons Attribution-NonCommercial licence (http://creativecommons.org/licenses/by-nc/4.0/), which permits non-commercial re-use, distribution, and reproduction in any medium, provided the original article is properly cited. The written permission of Cambridge University Press must be obtained prior to any commercial use. 
policymakers to favour positions that deviate from median voter preferences (Winter and May 2001).

Yet, dating back to Schattschneider (1935), scholars have also been concerned about how policy can impact the public's preferences. Research in this vein has typically examined welfare policies, particularly in the USA, with reference to whether the implementation of these policies changes mass public preferences and leads to positive policy feedback. In a variety of studies, researchers often find that the beneficiaries of policies become even more supportive over time, reinforcing the policies themselves (e.g. Pierson 2000; WEAVER 2010; Busemeyer 2013). ${ }^{1}$

However, as indicated by the term policy feedback, the highly endogenous relationship between policy and public opinion generates a significant empirical challenge in estimating the effect of one upon the other. When witnessing popular support of policies, are we witnessing policies fostering support amongst their beneficiaries, or the public at large? Or are we instead seeing that popular policies are more likely to be adopted?

To overcome this endogeneity challenge, we utilise an unexpected policy conflict over air pollution policy in New Delhi, where the judicial branch prevented a policy restricting the use of cars from being implemented if women were exempted. Beyond its usefulness from a research design perspective, many countries have adopted policies to manage vehicle usage in order to reduce urban air pollution and GHG emissions (McMullen 1993; Noonan 2014; Teague et al. 2015). Yet such policies are subject to controversy over their distribution of costs (Wicki et al. 2019), leading to political backlash.

Using survey experiments fielded shortly before and after the judicial intervention, we estimate the effect of this conflict between branches of government upon public support for various forms of the policy. We find that the executive-judiciary policy conflict moderately increased overall public support for the policy. However, this increase in support is a result of a polarisation in support. Women, those who would be exempted from the policy, increased their support for the policy after the judicial intervention but only if the policy includes these exemptions. Men, however, only increase their support for the policy in response to the policy conflict if it does not include these exemptions. Thus, "a new policy creates new politics" Schattschneider (1935), with the conflict between branches of government over policy design further reinforcing differences between genders in terms of policy support.

Hence, this article contributes to a variety of literatures seeking to understand the fundamental link between policy, politicians, and the public. First, we contribute to a large literature on understanding the relationship between policies and public opinion (e.g. Wlezien 1995; Pierson 2000; Campbell 2012; Busemeyer et al. 2019). Our results show that public opinion is responsive to policy, with a research design that limits problems of endogeneity faced in previous research. Furthermore, we highlight how overall feedback can mask a polarisation of support, contributing to recent efforts that seek to examine under which conditions groups of individuals respond favourably to policy actions (e.g. Branham 2018).

\footnotetext{
${ }^{1}$ Although see Busemeyer et al. (2019) for a recent example of research that provides a more nuanced version of policy feedback.
} 
Second, our article speaks to a literature on the effects of elite cues on public opinion. This research typically contrasts theories where political actors represent the views and demands of the public (Downs 1957; Page and Brody 1972; Loewen and Rubenson 2011) against theories where political elites are in fact able to shape public opinion (Abramowitz 1978; Gabel and Scheve 2007; Lenz 2009, 2012; Minozzi et al. 2015; Broockman and Butler 2017). Our results provide evidence for the latter: the positions of policy actors do indeed shape public opinion. However, we add further context to this literature by finding that support systematically varies along gendered or beneficiary lines, suggesting that responses to the specific positions adopted match individuals' existing interests.

Third, we add to a burgeoning literature on how policy costs create policy feedback. Scholars have typically focused on how policy implementation increases support amongst those parts of the public that benefit from it (Jacobs and Mettler 2018). Yet, citizens also experience policy costs, which can lead to negative policy feedback (Burch 2013; Lerman and Weaver 2014). Our results highlight how policy feedback can be polarised as a result of differing policy costs, particularly in this case where the benefits are diffused but the costs are concentrated. In this way, support for policies that offer benefits for all can nevertheless be stalled when policy costs are distributed unequally across citizens. Of course, this opposition can increase when citizens are organised along with interest groups, for example, trade unions. But even in the absence of such collective bodies that interpret policies and provide a focal point for collective action, citizens experiencing differential policy costs might oppose a given policy.

Fourth and finally, our article speaks to literature that examines the effect of clashes between branches of government on public opinion. Such conflict between branches of government occurs frequently in a variety of contexts. In the European Union, the European Parliament has often collided with the European Commission on a wide range of policies (Hayward 2012; Hix 2013). In the USA, there are many instances of conflict between the judiciary and state and federal governments (Moe and Gilmour 1995; Lewis 2005). Of course, not every clash gets much media attention and leads to active public debate. But when this happens, policy clashes can play an important role in shaping public opinion. In Brown v Board of Education (1954), for example, the US Supreme Court struck down race-based segregation in public schools, a policy supported by the state and local governments. This led to massive public protests in the Southern US states. And in Swann versus CharlotteMecklenburg Board of Education (1971), the US Supreme Court recognised that forced busing may be required to achieve racial desegregation. Arguably, when different branches of government take a unified position on a policy, polarisation of public opinion on the policy is discouraged and the event becomes less newsworthy. But when these branches clash, along with raising issue salience, this clash provides legitimacy to policy critics and may thus increase polarisation of public opinion.

In the remainder of the article, we start by outlining the empirical issue on which we focus, including the policy shock (clash between the executive and the judiciary) we exploit in our causal identification strategy. We then outline the theoretical mechanisms behind how the conflict between different branches of government can affect public opinion. Following that, we describe the study design, present the empirical findings, and offer some concluding thoughts. 


\section{Limiting air pollution in major cities}

Air pollution is one of the leading causes of death worldwide, with approximately 4 million people dying prematurely from it each year (Cohen et al. 2017). Nowhere is this more so than in large urban centres of developing or emerging economies. One prominent policy response to urban air pollution is the odd-even rule (Bernauer et al. 2018). Under this rule, private cars with odd and even registration numbers are allowed on roads only on alternate days (Goyal and Gandhi 2016; Mohan et al. 2017). The odd-even rule has been used previously in New Delhi. However, in New Delhi, the rule has exempted women. Thus, the odd-even rule imposes very tangible private costs on male car owners while creating health and other benefits from reduced air pollution and congestion that can be enjoyed by all, a classic challenge for many regulatory policies (Lowi 1964; Wilson 1980).

One key difference between New Delhi and other cities' use of the odd-even rule is the issue of exemptions. Most controversially in New Delhi, women were exempted from this policy in the 2016 trial phase. This exemption has generated considerable public debate, and became the focus of the subsequent clash between the executive and the judiciary when the Delhi government sought to introduce the odd-even rule on a permanent basis from 2017.

A follow-up attempt to implement this rule in Delhi occurred in November 2017. In response to persisting severe air quality problems, the Delhi government announced in October 2017 that it would reintroduce the odd-even rule starting 13-17 November 2017. However, during an initial hearing on 10 November 2017, the National Green Tribunal, NGT (India's environmental court: http:// www.greentribunal.gov.in) unexpectedly struck down the policy. In a special hearing on 11 November, following the revised petition of the government, it allowed the policy to be implemented but disallowed, exemptions for women and two wheelers. Rather than introducing the odd-even rule without exemptions, the Delhi government responded by withdrawing the policy altogether. We investigate how this clash in Delhi, which most observers and the public did not expect, influenced public opinion on the odd-even rule in general, and gender-based exemptions in particular.

\section{Theoretical mechanisms}

Enacting policies and regulations are amongst the foremost governmental function. But what areas or issues ought to be regulated, and how, and whether regulations will serve the intended purpose is often contested. Governments can seldom secure perfect compliance by relying on coercion alone (North 1990). The costs of enforcing regulations are lowered when those subject to regulation deem the latter to be appropriate, fair, and effective. Hence, along with designing and enacting regulations, governments invest much time and effort in securing normative compliance with their policies.

The study of public opinion on regulatory issues is therefore critical for governments to effectively perform their regulatory functions. As most policy problems can be addressed via different policy instruments, how the legitimacy and effectiveness of policy instruments is understood by those regulated therefore become an 
important area of inquiry. These instruments differ along several substantive dimensions. Take the case of debate over the effectiveness of command and control versus market-based approaches in environmental policy (Cole and Grossman 1999). These instruments are likely to differ in levels of effectiveness and asymmetrically impose costs and create benefits across actors. It is, therefore, not always clear which instrument will be acceptable to the plurality of regulated actors (in our case, citizens). After all, the smartest policy approaches that result in maximum net policy benefits can fail if they are deemed to be unfair and do not garner public support.

There is widespread recognition that policy framing and policy comprehension play an important role in influencing public support (Terkildsen and Schnell 1997; Jacoby 2000). However, the dominant focus of existing studies tends to be on how policy adoption and implementation are influenced by public opinion (e.g. Anderson et al. 2017). Typically, focusing on democratic countries, this line of research often finds that policies tend to match the public's preferences and attitudes, or at least certain segments of society, such as high-income groups (Gilens and Page 2014).

Yet, dating back to Schattschneider (1935), the benefits a policy can provide upon implementation can impact public preferences. Often referred to as positive policy feedback, the beneficiaries of policies become even more supportive over time, reinforcing the policies themselves (e.g. Pierson 2000; WEAVER 2010; Busemeyer 2013). In the case of the odd-even policy, we expect to observe differences between men and women before the policy conflict occurs. Exemptions for women should therefore significantly reduce support amongst men, who are the net losers from the enaction of the policy with exemptions. This leads to the following hypotheses:

H1a: The odd-even policy with exemptions will receive higher support from women.

H1b: The odd-even policy without exemptions will receive higher support from men.

\section{Elite-level policy conflict and mass policy polarisation}

The previous theoretical logic of policy feedback, in considering the impact of policy actions on individuals' policy preferences, considers that policy actors within "the government" speak with one voice, providing an unambiguous message to citizens. Of course, government actors may have major differences that they debate internally, as Allison (1971) described in his classic work on the Cuban missile crisis. But for the public audience, and in this stylised view, various units of the government speak with one voice with the expectation that this show of unity enhances the legitimacy of governmental action.

But what if various branches of government show open conflict about a policy, or a specific dimension of the policy (Flores and Barclay 2016)? How will citizens, whose support is essential to the viability of many policies the government is envisaging or actually implementing, respond?

First, elite-level policy disagreements can legitimise opposition amongst the public, by providing individuals' the ability to reference an elite-level justification. Therefore, in the case of the odd-even rule, the judiciary (NGT) legitimised 
objections to exemptions, thereby increasing opposition to the policy in this form. Various scholars note that in the USA, for instance, Supreme Court rulings enshrine policies with legitimacy (Scheingold 1974; Marshall 1987), given citizens' overall respect for the rule of law. While there is no systematic data, it seems that the judiciary in India enjoys substantial prestige and it often takes on the executive if the latter is unwilling to implement policies that are unpopular in key segments of society (Iyengar et al. 2018).

Exemptions for women were put in place to address a visible and salient problem of gender violence. A slew of sexual assaults in Delhi ${ }^{2}$ brought the issue of gender violence to the forefront and highlighted the risk women face when they use public transportation. The Delhi government was thus faced with demands for addressing the concerns of an important and vocal constituency: urban women. The odd-even rule, if applied to all, would force women to use public transportation, which might increase the risk of further sexual crimes. Hence, the decision to exempt women from this rule.

Therefore, the NGT's dismissal of the odd-even rule, on the ground of exemptions, may provide legitimacy to those who wish to express opposition to the exemptions but did not dare to do so before their views were legitimated by the NGT ruling.

Second, the threat of legitimised opposition to a policy will also increase the salience of the issue for initial beneficiaries of the policy. Conflict between branches of government may thus embolden the views of those who are beneficiaries of the policy. Individuals benefitting from the exemption, females, will also respond to the conflict between branches of government by increasing support for that particular policy design. Doing so serves as a countervailing force against the increasing support for alternative, less beneficial, versions of the policy.

Previous research argues that this often occurs in response to the actions of courts, particularly the US Supreme Court (Price and Keck 2015). For example, Price and Keck (2015) cite Judge Ginsberg's statement that Roe v. Wade reversed the trend of increasing acceptance of abortion, and instead generated backlash by mobilising "right to life" groups, as a result of "heavy-handed judicial intervention" that "was difficult to justify and appears to have provoked, not resolved, conflict". Indeed, the movement against the "activist judiciary" claims that unelected judges are making laws, as opposed to elected legislatures. Indeed, this sort of backlash has support even within the judiciary. The US Supreme Court justice Scalia (2018) was the leader of the originalist movement that insisted that justices must faithfully adhere to the constitution. If the law has to be changed, it must be done either through legislative action or through a process of the constitutional amendment.

Notably, for these policy conflicts to lead to policy polarisation, the issue at stake must be salient. There are frequently judicial-executive conflicts that fall under the public's radar, on a variety of issues that ultimately have little impact upon the public's policy preferences. The odd-even policy we examine, however, was highly salient for the public due to the high visibility of both the problem and the policy solution. First, as outlined in section 2, air pollution in New Delhi is a frequent and

\footnotetext{
${ }^{2}$ One of the highest profile cases was a gang rape case occurring in 2012 that garnered international media attention (e.g. https://india.blogs.nytimes.com/2012/12/18/outrage-in-delhi-after-latest-gang-rape-case).
} 
severe problem experienced by the public that has profound health consequences. Second, the policy response in the form of the odd-even policy imposes clear and visible constraints on individuals' everyday actions and mobility, in a manner that many other policies do not.

In this context of high salience, policy conflict may thus lead to significant policy polarisation. A judicial body intervening against the specific exemptions to the oddeven rule will embolden those who would benefit from these exemptions to further increase support and protect these privileges. In the context of the odd-even policy in New Delhi, this means that women will further increase their support of the policy with exemptions as a counterbalance against the increased opposition generated by the judicial intervention. This leads to the following hypotheses:

H2a: Support for the odd-even policy without exemptions will increase amongst men after the policy conflict.

H2b: Support for the odd-even policy with exemptions will increase amongst women after the policy conflict.

\section{Research design}

As noted previously, any empirical estimation of the effect of policymaker behaviour, including clashes between the executive and the judiciary, on the public's policy preferences faces an endogeneity challenge. That is, there is the possibility of an endogenous relationship between the public's policy preferences and policy action [in our specific case either by the court (NGT) or the Delhi government]. We need to rule out that branches of government do not take their respective policy positions in anticipation of prevailing public opinion. To address this challenge, we exploit the unexpected ruling against the odd-even rule by the NGT, and the subsequent withdrawal of the policy by the Delhi government. As outlined below, the unexpected nature of this ruling allows us to conceptualise it as a quasi-experimental treatment. It is this "shock" that we use to better estimate the causal impact of intragovernmental conflict over policy upon individuals' policy support. We do so by using original surveys that we fielded before and after the NGT ruling, and subsequent withdrawal of the policy by the Delhi government - without knowing that we would be able to scientifically benefit later on from the court decision.

The baseline survey (pre-NGT ruling) with 500 respondents was fielded on 1020 October 2017. The first wave of the survey, with 750 respondents, was fielded from 16 to 23 November 2017, shortly after the NGT ruling and the Delhi government's withdrawal of the odd-even rule plan. We then fielded a final wave with 750 respondents two weeks later, from 4 to 9 December 2017. These surveys were designed by the authors and fielded online by IPSOS. We used quota sampling in order for the sample to be broadly representative in terms of gender, occupation, age, and education. Given our sample sizes, this approach reduces the potential for imbalance on these observables.

In each survey, we embedded a series of vignette experiments dealing with the odd-even rule and its policy design, including the gender exemption. These vignettes are used to ensure that respondents across contexts have comparable conceptions of the odd-even policy they are rating. The vignette experiments consist of 
Table 1. Treatment design

\begin{tabular}{lcc}
\hline Application of the Odd-Even Rule & November-February & Permanent \\
\hline- & $V 1$ & $V 2$ \\
Women exempted & $V_{3}$ & V4 \\
Exemptions undermine effectiveness & $V 5$ & $V 6$ \\
\hline
\end{tabular}

two parts. The main focus is on information about gender exemptions. We randomly assigned study participants to any of the six vignettes that are a combination of two factors. First, the vignette contains information about the application of the odd rule, either: 1) no exemptions, (2); exemptions for women; or (3) exemptions for women, while noting this could undermine policy effectiveness. Second, we also include information about the time frame of the proposed odd-even rule, either being temporary (from November to February; the high pollution months) or permanent (year around). This ensures respondents have a common time frame in mind when thinking about the policy. ${ }^{3}$ This assignment was fully randomised. The exact wording was:

To what extent would you support or oppose the odd-even rule for cars [RANDOMLY ASSIGN: 1. "on a permanent basis" or 2. "during the months of November to February"] [RANDOMLY ASSIGN: 1. "?" (control group) or 2. ", if women were exempted from this rule and could drive their car on any day of the week?" or 3. ", if women were exempted from this rule and could drive their car on any day of the week? This would result in more air pollution and congestion than if women were not exempted."]

Table 1 summarises the treatment conditions.

The response scale (support for the odd-even rule) ranged from strongly support (4) to strongly oppose (1). For covariate adjustment, we consider a number of variables that may also impact policy preferences in general and preferences concerning the odd-even rule specifically to increase the efficiency of our estimation, and adjust for any imbalances resulting from allocation to treatment conditions. These include socio-demographic variables such as age, education, gender, and income, as well as items directly related to air pollution and the odd-even policy, such as car ownership, and whether they have experienced a health problem due to air pollution. ${ }^{4}$

We use a before-after design in order to estimate the effect of the policy conflict upon individuals' policy support. To ensure comparability between respondents before and after the policy conflict, and increase the credibility of our causal estimates, we use matching (Ho et al. 2007). ${ }^{5}$ We match respondents in the "treatment" group, those surveyed after the policy conflict, with respondents who were surveyed before the conflict (the "control" group) based upon their age, education, gender,

\footnotetext{
${ }^{3}$ For the empirical analysis, we pool these time differences in the treatment to ensure adequate statistical power to identify the gender effect.

${ }^{4}$ In the appendix, we provide item wordings and show that these variables are balanced across treatment conditions.

${ }^{5}$ Balance statistics for the matched sample are displayed in Appendix E
} 
Table 2. Determinants of support for odd-even rule - baseline survey

\begin{tabular}{lccc}
\hline & No Exemptions & With Exemptions & With Exemptions (+ Prime) \\
\hline Female & -0.18 & -0.01 & 0.08 \\
& $(0.15)$ & $(0.18)$ & $(0.15)$ \\
Age & -0.13 & $0.46^{\star \star \star}$ & 0.06 \\
& $(0.14)$ & $(0.17)$ & $(0.15)$ \\
Income & 0.05 & -0.18 & 0.09 \\
& $(0.12)$ & $(0.18)$ & $(0.15)$ \\
Own car & $0.66^{\star \star \star}$ & 0.02 & 0.01 \\
& $(0.20)$ & $(0.18)$ & $(0.16)$ \\
Car in household & -0.02 & 0.03 & -0.03 \\
& $(0.15)$ & $(0.17)$ & $(0.14)$ \\
Health problems & $0.30^{\star \star}$ & $0.28^{\star}$ & $0.71^{\star \star \star}$ \\
& $(0.13)$ & $(0.16)$ & $(0.13)$ \\
Intercept & $3.20^{\star \star \star}$ & $2.89^{\star \star \star}$ & $3.08^{\star \star \star}$ \\
& $(0.06)$ & $(0.07)$ & $(0.06)$ \\
Matching & No & No & No \\
Num. obs. & 156 & 169 & 159 \\
\hline
\end{tabular}

Notes: Robust standard errors are in parentheses. ${ }^{* *} \mathrm{p}<0.01,{ }^{* *} \mathrm{p}<0.05,{ }^{*} \mathrm{p}<0.1$.

Variables are rescaled with mean zero, thus the intercept shows the average rating for the odd-even policy.

income, whether they personally or their household owns a car, and whether they have experienced a health problem due to air pollution. The similarity between respondents is calculated using Mahalanobis distance, from which respondents are matched according to their "nearest" neighbour. This matching is conducted with replacement to ensure the most appropriate match for each treated individual. We then estimate the following equation, using the matching weights, by weighted least squares

$$
y=\beta_{0}+\beta_{1} \text { PostConflict }+Z \gamma+\epsilon
$$

where our effect of interest is $\beta_{1}$, the effect of the policy conflict upon policy support $(y)$. To increase statistical power, we pool waves 1 and 2 together, however, as a robustness test, we conduct a reanalysis where we only include wave 1 respondents.

\section{Results}

Before estimating the effect of the policy conflict between the executive and the judiciary upon policy support, we show how individuals' characteristics are associated with support for the odd-even policy before the policy conflict occurred. Table 2 displays the results from these regressions. The results suggest that while respondents' sex is associated with policy support, in the manner suggested by our theoretical argumentation based upon policy feedback ( $\mathrm{H} 1 \mathrm{a}$ and $\mathrm{H} 1 \mathrm{~b})$, these effects are not statistically significant. In the absence of policy conflict increasing the stakes of policy design, females only weakly prefer a policy with exemptions and oppose a policy without exemptions.

Turning to the other covariates, interestingly car ownership is a significant determinant of support for an odd-even policy without exemptions. Given the previous context of exemptions being granted in New Delhi, this suggests that opposition may arise not due to the policy's goal to reduce traffic and air pollution, but rather 
Table 3. The effect of the policy conflict upon support for odd-even rule

\begin{tabular}{lccc}
\hline & No Exemptions & With Exemptions & With Exemptions (+ Prime) \\
\hline Policy conflict & 0.14 & 0.22 & $-0.16^{\star}$ \\
Intercept & $(0.11)$ & $(0.15)$ & $(0.10)$ \\
& $3.22^{\star \star \star}$ & $2.85^{\star \star \star}$ & $3.24^{\star \star \star}$ \\
Matching & $(0.11)$ & $(0.14)$ & $(0.09)$ \\
Num. obs. & Yes & Yes & Yes \\
\hline
\end{tabular}

Notes: Robust standard errors are in parentheses. ${ }^{\star \star *} \mathrm{p}<0.01 ;{ }^{* \star} \mathrm{p}<0.05 ;{ }^{\star} \mathrm{p}<0.1$.

perceptions of "unfair" treatment. Otherwise, a consistent determinant of support for odd-even policies is an individuals' health. Individuals experiencing health problems as a result of air pollution are more likely to support policy efforts to deal with this.

We now turn to examining whether the policy conflict changed the overall support for the odd-even policy. Table 3 displays the estimated effect of the policy conflict upon policy support in terms of the difference in support for forms of the oddeven policy before and after the policy conflict. There is a statistically significant negative effect for exemptions when respondents were primed about how they reduce the effectiveness of the policy. Substantively, the negative estimate of -0.17 for a 4 -point Likert scale outcome corresponds to $5 \%$ of the maximum possible effect of a variable. Therefore, in the context of policy conflict over air pollution, highlighting how policy design may not adequately address the problem does lead to a decline in support.

The results suggest that there was a small, but not statistically significant, increase in support for the odd-even policy, both with and without exemptions. However, this result is not surprising, both when we consider that this effect is pooling female and male respondents and that the salience of dealing with air pollution increased within this time frame. If there is indeed a polarisation in policy support caused by the policy conflict, then we should expect a weak average effect as male and female support cancels each other out.

To examine whether this average effect is the result of polarisation between female and male respondents, we include an interaction effect to allow the effect of the policy conflict to vary by sex. Figure 1 shows the relevant marginal effects for understanding whether the policy conflict-affected policy support depending on an individuals' sex. The first panel displays the effect of the policy conflict, conditional upon sex. We can see some evidence that there was a polarisation by sex in support for the type of odd-even rule. The policy conflict causes females to be more supportive of the policy with exemptions (in line with $\mathrm{H} 2 \mathrm{~b}$ ), while males become more supportive of the policy with no exemptions (in line with $\mathrm{H} 2 \mathrm{a}$ ). However, both sexes respond negatively to exemptions when primed about their potential to reduce the efficacy of the policy.

The second panel displays the effect of being female upon policy support, conditional upon the time period. Post-conflict, there is a striking difference between female and male support for an odd-even rule with exemptions. The marginal effect for females is approximately 0.35 , which corresponds to $12 \%$ of the maximum 


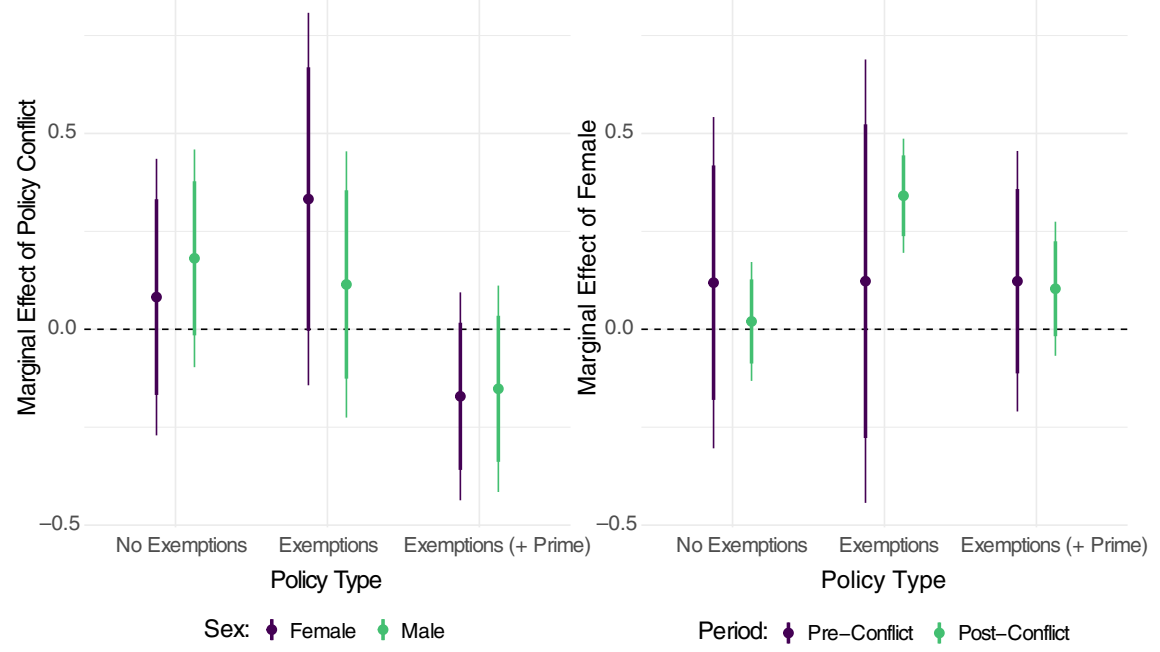

Figure 1 The effect of policy conflict upon support varies by sex. The effect of the judicial government policy conflict is the difference in support for the odd-even rule after and before the policy conflict. Notes: Points indicate marginal effects, which are computed from the regression models are displayed in Table A.3. Lines indicate $83.4 \%$ and $95 \%$ confidence intervals.

possible effect on a 4-point Likert scale. While there may have been some initial difference between female and male respondents before the conflict, this significantly changes as a result of the policy conflict. Women also tend to generally be more supportive of the odd-even policy, across differing designs and time periods, although these differences are small and not statistically significant.

Taken together, these results support our theoretical logic of policy polarisation amongst females and males in response to the government-judicial policy conflict. When examining average support for the odd-even policy both with and without exemptions for women, we see a weak increase after the executive-judiciary conflict. This reflects an overall preference amongst individuals for dealing with the problem of air pollution. However, preferences concerning the specific form of policy depend upon whether they are male or female, and the executive-judiciary conflict contributed to polarisation in this regard.

\section{Robustness}

We also conduct a number of robustness tests to assess the stability of our results. First, one could be concerned that attention surrounding the odd-even policy was generally increasing over time, and not the unexpected shock we claim as caused by the policy conflict. To lend support to our interpretation of this, we can use Google trends to see interest in the odd-even rule over a broad period of time. Figure 2 shows that interest peaked at the time of the policy conflict, and was low beforehand. Therefore, we can be confident that our baseline surveys in New Delhi did not capture a general trend for increasing interest in the odd-even policy, with interest only occurring after the baseline when the policy conflict occurred. 


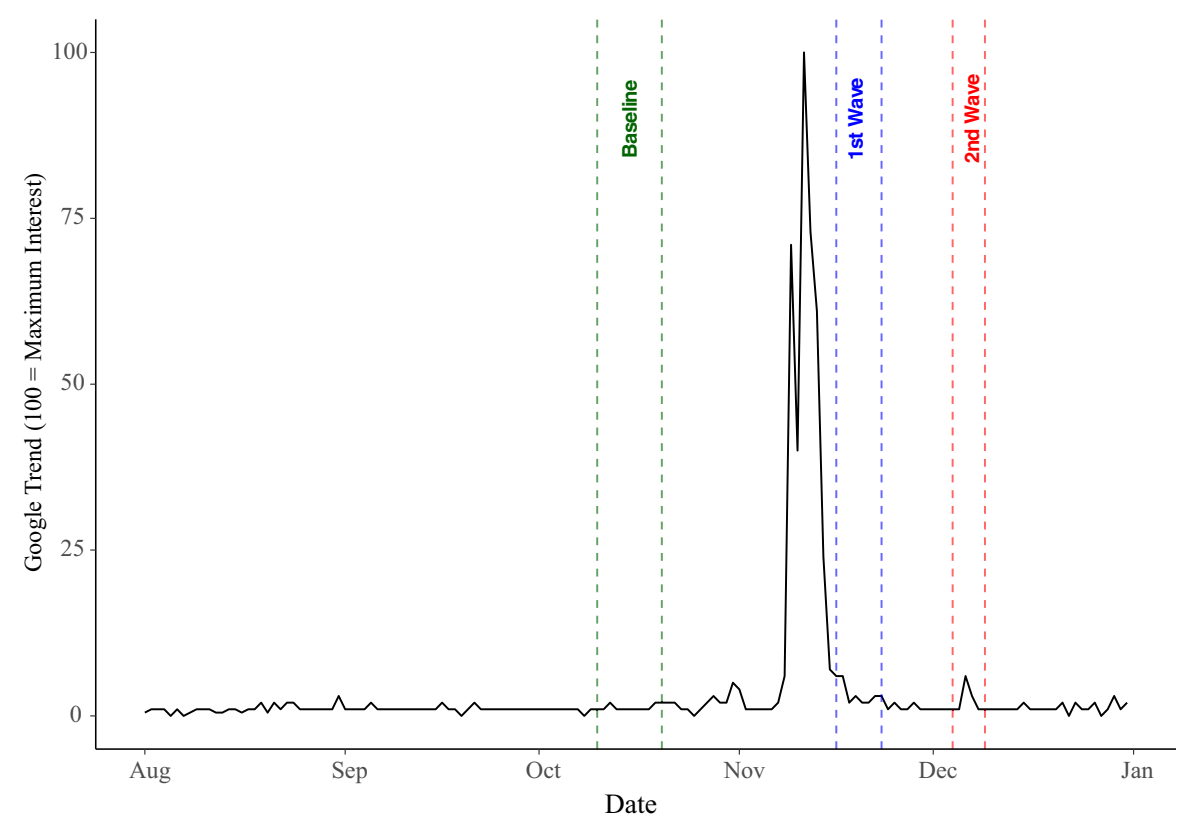

Figure 2 Google trends data on searches for the term "odd even" in New Delhi.

Second, one may be concerned that pooling the two post-conflict waves together is inappropriate, as wave 2 is further removed from the conflict (and the baseline) survey. Therefore, we reconduct the analyses omitting wave 2 . As displayed in the appendix, we find similar results as shown in Figure 1. Third, we show this effect did not also occur in other cities facing air pollution at the same by conducting a Difference-in-Differences analysis, utilising concurrent surveys in Beijing. ${ }^{6}$ In doing so, we continue to find a similar pattern in the results, with support for the oddeven policy polarising by sex as a result of the policy conflict.

\section{Conclusion}

A large literature in public policy focuses on how individual and collective-level factors influence policy preferences of the mass public in a wide range of areas, and how those policy preferences (or public opinion in general) affect government behaviour. The research presented here brings new evidence to a body of research that complements the aforementioned studies by examining the public opinionpolicy process relationship from the other end: it focuses on how the behaviour of policymakers and public institutions influences the public's policy preferences. Specifically, we study how clashes between key institutions of government, in our case the executive and the judiciary, influence the public's policy preferences.

${ }^{6}$ Results are displayed in Supplementary Material. 
We outlined a set of theoretical arguments for how such clashes, which are common in most democratic countries, can impact on the public's policy preferences. Importantly, these clashes may polarise public opinion. By legitimising opposition and threatening beneficiaries, individuals may become more supportive of the policy design that favours them. Focusing on the unexpected dismissal of a highly salient government policy (the odd-even rule) in Delhi by the judiciary, we find that policy conflict does indeed have a polarising effect that, in our case, runs along gender lines. Specifically, the executive-judiciary conflict increased support by men for a version of the odd-even rule without exemptions for women, whereas it bolstered policy support amongst female citizens for a version of the odd-even rule with exemptions for women. Importantly, while there were differences between females and males for the use of policy with and without exemptions before the conflict, this was not particularly strong. This suggests that individuals become particularly sensitive towards policy design when their potential benefits are challenged.

Our empirical analysis focuses on a particular policy issue (the odd-even rule and urban air pollution) in New Delhi. Systematic analysis of how such clashes between the executive and the judiciary affect public opinion requires high-quality public opinion data for the time period before and after the clash, which is often not available. Moreover, even if such data are available (e.g. in the case of Brexit, or the US racial policy issues mentioned previously), the endogeneity challenge remains. We thus focused on an empirical case for which we have original survey data covering a time span before, during, and after an executive-judiciary clash, and where this clash occurred unexpectedly (for us, and for our survey participants) during data collection. The latter condition allows us to reduce the endogeneity problem by using a before-after design with matching.

Nevertheless, the empirical evidence for the theoretical arguments and analytical approach could serve as a template for studying the broader question of how the behaviour of policymakers and conflicts amongst different parts of government influence policy preferences amongst the mass public. Research along the lines presented here can also generate important case-specific policy insights. In our case, we find that gender-based exemptions - besides reducing policy effectiveness - are also likely to affect overall public support for the odd-even rule and increase gender-based polarisation of policy preferences. This suggests that exemptions that are not aligned with the policy goal, in this case reducing air pollution, can have significant implications for the political feasibility of a policy intervention.

Supplementary material. To view supplementary material for this article, please visit https://doi.org/10. 1017/S0143814X2100012X.

Acknowledgements. We thank participants at the Symposium on Behavioral Approaches to Bureaucratic Red Tape and Administrative Burden, George Washington University and the Annual Conference of the Swiss Political Science Association for their feedback. This research was financially supported by European Research Council (ERC) Advanced Grant No. 295456 (Sources of Legitimacy in Global Environmental Governance) and ETH Zürich.

Data Availability Statement. Replication materials are available in the Journal of Public Policy Dataverse at https://doi.org/10.7910/DVN/NO8R83. 


\section{References}

Abramowitz AI (1978) The Impact of a Presidential Debate on Voter Rationality. American Journal of Political Science, 22(3): 680-690. doi: 10.2307/2110467.

Allison G (1971) The Essence of Decision. Boston: Little Brown.

Anderson B, Böhmelt T and Ward H (2017) Public opinion and environmental policy output: a crossnational analysis of energy policies in Europe. Environmental Research Letters, 12(11). doi: 10.1088/ 1748-9326/aa8f80.

Bernauer T, Prakash A and Beiser-McGrath LF (2018) Do Exemptions Undermine Environmental Policy Support? An Experimental Stress Test on the Odd-Even Road Space Rationing Policy in India. Regulation \& Governance. doi: 10.1111/rego.12225.

Bishin BG, Hayes TJ, Incantalupo MB and Smith CA (2016) Opinion Backlash and Public Attitudes: Are Political Advances in Gay Rights Counterproductive? American Journal of Political Science, 60, 625-648.

Branham JA (2018) Partisan Feedback: Heterogeneity in Opinion Responsiveness. Public Opinion Quarterly, 82(4): 625-640. doi: 10.1093/poq/nfy040.

Broockman DE and Butler DM (2017) The Causal Effects of Elite Position-Taking on Voter Attitudes: Field Experiments with Elite Communication. American Journal of Political Science, 61(1): 208-221. doi: 10.1111/ajps.12243.

Brooks C and Manza J (2007) Why Welfare States Persist. The Importance of Public Opinion in Democracies. Chicago: Chicago University Press.

Burch T (2013) Trading Democracy for Justice: Criminal Convictions and the Decline of Neighborhood Political Participation. Chicago: University of Chicago Press.

Busemeyer MR (2013) Education Funding and Individual Preferences for Redistribution, European Sociological Review, 29(6): 1122-1133. doi: 10.1093/esr/jcs085.

Busemeyer MR, Abrassart A and Nezi R (2019) Beyond Positive and Negative: New Perspectives on Feedback Effects in Public Opinion on the Welfare State. British Journal of Political Science. doi: 10. 1017/S0007123418000534.

Campbell AL (2012) Policy Makes Mass Politics. Annual Review of Political Science 15(1): 333-351. doi: 10. 1146/annurev-polisci-012610-135202.

Cohen AJ et al. (2017) Estimates and 25-Year Trends of the Global Burden of Disease Attributable to Ambient Air Pollution: An Analysis of Data from the Global Burden of Diseases Study 2015. The Lancet, 389(10082): 1907-1918.

Cole D and Grossman P (1999) When is Command-and-control Efficient-Institutions, Technology, and the Comparative Efficiency of Alternative Regulatory Regimes for Environmental Protection. Wisconsin Law Review, 887.

Downs A (1957) An Economic Theory of Democracy. New York: Harper.

Ewick P and Silbey S (2003) Narrating Social Structure: Stories of resistance to legal authority. American Journal of Sociology, 108(6): 1328-1372.

Flores AR and Barclay S (2016) Backlash, Consensus, Legitimacy, or Polarization: The Effect of Same-Sex Marriage Policy on Mass Attitudes. Political Research Quarterly, 69(1): 43-56. doi: 10.1177/ 1065912915621175.

Gabel M and Scheve K (2007) Estimating the Effect of Elite Communications on Public Opinion Using Instrumental Variables. American Journal of Political Science, 51(4): 1013-1028. doi: 10.1111/j.15405907.2007.00294.x.

Gilens M and Page B (2014) Testing Theories of American Politics: Elites, Interest Groups, and Average Citizens. Perspectives on Politics, 12(3): 564-581. doi: 10.1017/S1537592714001595.

Goyal P and Gandhi G (2016) Assessment of Air Quality During the 'Odd-Even Scheme' of Vehicles in Delhi. Indian Journal of Science and Technology, 9(48): 1-7.

Hayward J (2012) The Crisis of Representation in Europe. Oxon, United Kingdom: Routledge.

Hix S (2008) What's Wrong with the Europe Union and How to Fix it. Cambridge, United Kingdom: Polity.

Ho D, Imai K, King G and Stuart EA (2007) Matching as Nonparametric Preprocessing for Reducing Model Dependence in Parametric Causal Inference. Political Analysis, 15, 199-236.

Iyengar S, Dolšak N and Prakash A (2018) Should India's Supreme Court enforce regulations? The Regulatory Review, March 27. 
Jacobs L and Mettler S (2018) When and How New Policy Creates New Politics: Examining the Feedback Effects of the Affordable Care Act on Public Opinion. Perspectives on Politics, 16(2): 345-363. doi: 10. $1017 /$ S1537592717004182.

Jacoby W (2000) Issue Framing and Public Opinion on Government Spending. American Journal of Political Science, 750-767.

Klarman M (2013) From the Closet to the Altar: Courts, Backlash, and the Struggle for Same-Sex Marriage. New York: Oxford University Press.

Lenz GS (2009) Learning and Opinion Change, Not Priming: Reconsidering the Priming Hypothesis. American Journal of Political Science 53(4): 821-837. doi: 10.1111/j.1540-5907.2009.00403.x.

Lenz GS (2012) Follow the Leader?: How Voters Respond to Politicians' Policies and Performance. University of Chicago Press.

Lerman AE and Weaver VM (2014) Arresting Citizenship: The Democratic Consequences of American Crime Control. Chicago: University of Chicago Press.

Lewis G (2005) Same-Sex Marriage and the 2004 Presidential Election. PS: Political Science \& Politics, 38(2): 195-199. doi: 10.1017/S1049096505056295.

Loewen PJ and Rubenson D (2011) For want of a nail: Negative persuasion in a party leadership race. Party Politics, 17(1): 45-65. doi: 10.1177/1354068810372564.

Lowi T (1964) American Business, Public Policy, Case Studies, and Political Theory. World Politics, 16, 677-715.

Marshall TR (1987) The Supreme Court as an Opinion Leader: Court Decisions and the Mass Public. American Politics Quarterly. 15(1):147-168. doi: 10.1177/1532673X8701500107.

McMullen BS (1993) Congestion Pricing and Demand Management: A Discussion of the Issues. Policy Studies Journal, 21: 285-295. doi: 10.1111/j.1541-0072.1993.tb01822.x.

Minozzi W, Neblo MA, Esterling KM and Lazer DMJ (2015) How leaders persuade constituents. Proceedings of the National Academy of Sciences, 112(13): 3937-3942. doi: 10.1073/pnas. 1418188112.

Moe RC and Gilmour RS (1995) Rediscovering Principles of Public Administration: The Neglected Foundation of Public Law. Public Administration Review, 55(2): 135-146. doi: 10.2307/977179.

Mohan D, Tiwari G, Goel R, and Lakhar P (2017) Evaluation of the Odd-Even Day Traffic Restriction Experiments in Delhi, India. No. 17-04218. 2017.

Noonan DS (2014) Effects of Ozone Alerts. Policy Studies Journal, 42, 122-145. doi: 10.1111/psj.12045.

North D (1990) Institutions, Institutional Change, and Economic Performance. Cambridge University Press.

Page B and Brody R (1972) Policy Voting and the Electoral Process: The Vietnam War Issue. American Political Science Review, 66(3): 979-995. doi: 10.2307/1957489.

Pavani V, and Aryasri AR (2016) Pollution Control through Odd-Even Rule: A Case Study of Delhi. Indian Journal of Science, 23, 403-411.

Pierson P (2000) Increasing Returns, Path Dependence, and the Study of Politics. The American Political Science Review, 94(2), 251-267. doi: 10.2307/2586011.

Price R and Keck T (2015) Movement Litigation and Unilateral Disarmament: Abortion and the Right to Die. Law \& Social Inquiry, 40, 880-907.

Scalia A (2018) A Matter of Interpretation: Federal Courts and the Law. Princeton, New Jersey: Princeton University Press.

Scheingold SA (1974) Europe in the Making. Western Political Quarterly, 27(2): 360-362. doi: 10.1177/ 106591297402700230.

Shane P (2009) Madison's Nightmare: How Executive Power threatens American Democracy. Chicago, Illinois: University of Chicago Press.

Stoddard T (1997) Why Gay people should seek the right to Marry. In M. Blasius and S. Phelan (eds.), We Are Everywhere: A Historical Sourcebook of Gay and Lesbian Politics. New York: Routledge, 753-756.

Teague WS, Zick CD and Smith KR (2015) Soft Transport Policies and Ground-Level Ozone: An Evaluation of the "Clear the Air Challenge" in Salt Lake City. Policy Studies Journal, 43, 399-415. doi: 10.1111/psj.12105.

Terkildsen N and Schnell F (1997) How Media Frames Move Public Opinion: An Analysis of the Women's Movement. Political Research Quarterly, 50, 879-900. 
WEAVER K (2010) Paths and Forks or Chutes and Ladders?: Negative Feedbacks and Policy Regime Change. Journal of Public Policy, 30(2), 137-162. doi: 10.1017/S0143814X10000061.

Wicki M, Huber R and Bernauer T (2019) Can Policy-packaging Increase Public Support for Costly Policies? Insights from a Choice Experiment on Policies against Vehicle Emissions. Journal of Public Policy, 1-27. doi: 10.1017/S0143814X19000205.

Wilson J (ed.) (1980) The Politics of Regulation. New York: Basic Books.

Winter S and May P (2001) Motivation for Compliance with Environmental Regulations. Journal of Policy Analysis and Management, 20(4): 675-698.

Wlezien C (1995) The Public as Thermostat: Dynamics of Preferences for Spending. American Journal of Political Science 39(4): 981-1000. doi: 10.2307/2111666.

Cite this article: Beiser-McGrath LF, Bernauer T, and Prakash A (2022). Do policy clashes between the judiciary and the executive affect public opinion? Insights from New Delhi's odd-even rule against air pollution. Journal of Public Policy 42, 185-200. https://doi.org/10.1017/S0143814X2100012X 